\title{
Resilience in occupational therapy students
}

\author{
*Patricia Ann de Witt, National Diploma in Occupational Therapy (Pretoria), MSc OT (Wits) PhD (Wits) \\ https://orcid.org/0000-0003-36 / 2-0920 \\ Sessional Senior Lecturer, Department of Occupational Therapy, School of Therapeutic Science, Faculty of Health Sciences, \\ University of the Witwatersrand
}

Luther Monareng, BSc OT (Wits) MSc OT (Wits) https://orcid.org/0000-000 I-6780-2436

Lecturer, Department of Occupational Therapy, School of Therapeutic Science, Faculty of Health Sciences University of the Witwatersrand

\author{
** Aaishah AH Abraham, BSc OT (Wits) https://orcid.org/0000-000 I-9762-9056 \\ Occupational Therapist, Bheki Mlangeni District Hospital
}

\section{**Safiyya Koor, BSc OT (Wits) https://0000-0002-5924-8073}

Occupational Therapist, Chris Hani Baragwanath Academic Hospital

\section{**Rizwana Saber, BSc OT (Wits) https://orcid.org/0000-0003-1325-0343 \\ Occupational Therapist, Orion College Remedial School}

*** $4^{\text {th }}$ Year students in the Department of Occupational Therapy, School of Therapeutic Science, Faculty of Health Sciences University of the Witwatersrand, at the time the study was conducted

At the University of the Witwatersrand, occupational therapy undergraduate students perceived their programme to be more stressful than similar health science education programmes, resulting in students experiencing mental health issues.

Thus, the purpose of this study was to determine the level of resilience and stress and health behaviours of students registered in the undergraduate Occupational Therapy programme.

A descriptive quantitative cross-sectional on-line survey design was used, replicating an American study of nursing students by Ahern. Permission was obtained from Ahern to use the same battery of data collection tools: demographic questionnaire, the resiliency scale; the perceived stress visual analogue scale and the health behaviours questionnaire. Once ethical clearance was obtained, the data collection battery plus an information sheet was mailed electronically to 205 students.

The three questionnaires were scored as prescribed and all other data were analysed descriptively. The Kruskal-Wallis ANOVA was used to test the significant difference between the variables and Spearman's rank order correlation coefficient to determine associations between the questionnaires as well as the subtests.

One hundred and seventeen questionnaires were analysed. Results indicated high stress levels within this cohort, with the major stressor being academic. Most students reported a medium level of resilience and the health behaviour questionnaire revealed a low risk. There was no significant difference between the different years and the only variables found to have a significant association was stress over the year increasing risk-taking behaviours.

It was concluded that all students could benefit from some resilience training. Those who lived away from home and had poor social support were the most vulnerable.

Key words: Resilience, Stress, Occupational therapy students

\section{INTRODUCTION}

Literature reports that tertiary health professional education is stressful, raising concerns about student mental health, both nationally and internationally ${ }^{1-4}$. Students in health science programmes experience stress related to time management, dealing with excessive workloads, academic deadlines and the fast pace of teaching and learning. Coping with the emotional demands of care when dealing with patients in under-resourced health care facilities during the clinical components of their curriculum adds to student stress. These stressors seem to increase with progression through the education programmes, frequently resulting in high levels of exhaustion and burnout, particularly in the later years ${ }^{4}$. Personality traits such as conscientiousness (common in health science students), has also been reported to contribute to student stress ${ }^{2}$.
In South Africa, it has been reported that many university students have other stressors in addition to their educational challenges and fear of failing, which may include financial and accommodation concerns. Other challenges they face include poverty, family ill-health and death associated with South Africa's burden of disease as well as family violence and discord, general violence and criminality ${ }^{2,5,6}$. Being responsible for looking after themselves and high family expectations are reported to increase their already high stress levels ${ }^{5-7}$. Many students are first generation university students with concerns about language proficiency and being far from home, the university environment and administration processes, which have also been reported to add to stress levels ${ }^{5,8-10}$.

A 2017 study conducted at the University of the Free State reported a $29.5 \%$ prevalence of moderate to extreme stress lev- 
els in students within their Health Sciences Faculty and a $26.5 \%$ prevalence of severe depression and anxiety ${ }^{2}$, which is somewhat higher than the figures reported in studies in the USA'. Other studies have also found female students to experience slightly higher stress levels than males ${ }^{1,2}$ as well as the fact that they perceived stress differently ${ }^{10}$. Students studying occupational therapy perceive their educational programmes to be especially stressful, with international studies dating from as early as the 1970's, reporting that the majority of these students experience higher than average stress levels ${ }^{11,12}$. Their stressors are reported to be associated with feelings of being overwhelmed and confusion due to the high programme demands, being underprepared for university level education, as well as complex academic staff-student relationships. The complexity of specific prescribed subjects such as anatomy and physiology, poor professional identity, low professional confidence and limited professional recognition have also been reported as contributing to their stress ${ }^{5,11,13-17}$. Other high stress demands result from the 1000 hours of hands-on-clinical experience prescribed as essential for their clinical competence ${ }^{14,18}$.

Occupational therapy students registered at the University of the Witwatersrand (Wits) in South Africa also believe that they have much higher stress levels than students in other comparative programmes in the Health Science Faculty at this university. They have been concerned with the increasing number of their classmates needing both educational and social support with anecdotal reports that more than half the students were taking some form of medication for mental health concerns such as depression and anxiety.

Hence, the purpose of this study was to determine the level of resilience and stressors of students registered in the Wits Occupational Therapy programme with the longer-term goal being to develop a strategy to assist students to develop resilience to cope with their perceived high stress levels. Three objectives were formulated to guide this preliminary research:

* To determine levels and sources of stress of all students registered in the programme;

* To determine the resilience levels and health behaviours of all students registered in the programme and compare the resilience levels and health behaviours of students in each of the four years of study;

* To determine the association between stress and resilience and the health behaviours of these students.

Literature suggests one of the ways in which occupational therapy students overcome or counteract stress and burnout is through the development of professional resilience and selfcare ${ }^{19,20}$. While there is controversy in the literature on the role personality characteristics may play in the resilience of individual students, there is agreement that both resilience and taking responsibility for health behaviours play a role in overcoming high stress demands. Resilience can be learnt, which improves performance in the work place ${ }^{7,21,22}$

\section{LITERATURE REVIEW}

Resilience to cope with academic stressors at institutions of higher learning has gained attention in recent years $\mathbf{s}^{3,18,23,24}$. Resilience has been defined as both an ability and a process. Resilience reportedly protects individuals from high stress and enables them to recover from adverse life situations and adapt to chronic hardship ${ }^{18,24,25}$. Resilience is the dynamic process of maintaining normal psychological and physical functioning when an individual experiences high stress and hardship. Resilience is reported to also modify inadequate coping mechanisms and abnormal stress responses ${ }^{24}$.

All occupational therapy students are exposed to academic stressors and many experience personal stressors to different degrees. They also face difficult and sometimes traumatic professional stressors during the course of the clinical education, such as the death, multiple trauma, severe mental or physical disability and person- inflicted harm as well as occupational injustice in the people they service ${ }^{26}$. Some students cope with the stress better than others and this has been associated with individual resilience ${ }^{24}$. This includes the way students perceive their stressors, their reaction to the stressor and the way they moderate their stressors ${ }^{24}$.

Resilient individuals have been described in the literature as curious, open, optimistic, fun loving ${ }^{27}$, having a sense of humour, a high level of self-awareness ${ }^{19}$, and artistic-social personalities ${ }^{28}$, being able to say no and to detach from their studies ${ }^{29}$, as well as bouncing back from adversity adeptly ${ }^{22}$. McAllister and McKinnon add that resilient individuals have an internal locus of control, have a sound self-concept, have inner wisdom and existential spirituality, are empathetic and are competent at organising daily activities ${ }^{3}$. Resilience is also reported to be fostered by factors such as supportive and extended family, friendship interactions, positive teaching and learning experiences, effective teacher-student relationships, good role-models, mentors and formal educational support systems ${ }^{7}$. These have also been named protective factors ${ }^{30}$.

While some characteristics of resilience may be associated with personality, literature reports that resilience can be learnt and most individuals can acquire resilience through taking responsibility for health behaviours using a cognitive behavioural approach ${ }^{3,22}$. McAllister and McKinnon advocate that this can be achieved in occupational therapy teaching and learning contexts through using a transformative educational environment in addition to critical constructive thinking ${ }^{3}$. Other authors advocate teaching student's mindfulness ${ }^{19}$, promoting emotional intelligence ${ }^{26}$ and replacing stressful challenges with positive coping strategies in clinical education contexts ${ }^{18}$ to build and teach occupational therapy students resilience.

Ahern and Norris have reported that the relationship between stress, resilience and protective factors in students within tertiary education programmes is complex and the stage of development of students is an important consideration ${ }^{30}$. Most students admitted to occupational therapy courses in South Africa proceed straight from school and thus the average age range of students is from 1821 years over the four years of study. This age range, according to Ahern and Norris, falls into late adolescence, a turbulent life phase, making them particularly vulnerable to the stressors of a tertiary education programme ${ }^{30}$.

In their research on resilience in late adolescent nursing students in Community Colleges in the USA Ahren and Norris ${ }^{30}$ used a conceptual model based on the Protection-Vulnerability Model of Resistance described by Garmezy, Masten and Tellegen ${ }^{31}$ and Luthar $^{32}$. This Protection-Vulnerability Model is based on developmental theory and considers coping with stress, resilience and protective factors to vary with development. In the conceptual model (Figure I) Ahern and Norris defined stress as the considered response to perceived stressors (academic and personal) that is moderated by both resilience (which is considered a trait and not a process or outcome) and protective factors, which are a combination of behaviours and supportive contextual circumstances ${ }^{30}$.

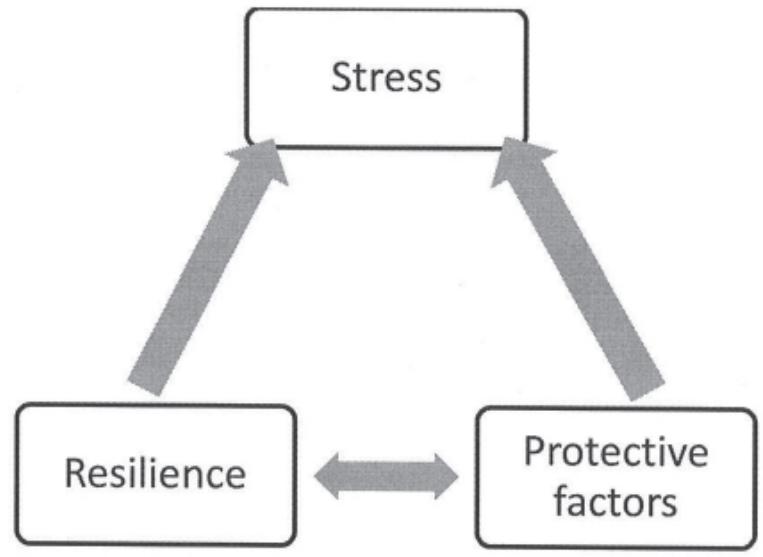

Figure I: Ahern and Norris's adaptation of the Protection-Vulnerability Model of Resilience ${ }^{30}$ 
Although literature has reported strategies to facilitate the development of resilience in occupational therapy students experiencing education programmes stress ${ }^{8,18,19}$, there have been no reported South African studies that have explored the relationship between stress and resilience in occupational therapy students. This study was planned to inform the introduction of a programme to build or develop resilience to mitigate the perceived high stress level experienced by Wits occupational therapy students during their undergraduate years.

Both the Wits Occupational Therapy Department as well as the University's Human Research Ethics Committee (Medical) approved this study [MI4096I]. The Assistant Dean of Student Affairs of the Health Sciences Faculty gave permission for the students' participation in this study.

\section{RESEARCH METHODS}

A descriptive quantitative cross-sectional survey design was used in this study. The resilience and stress levels as well as health behaviours of undergraduate occupational therapy students registered at the University of the Witwatersrand in South Africa were captured numerically on a Likert scale. Data were collected at one point in time. The resilience of each year cohort of students was compared, as was their perceived stress levels and reported health behaviours. This survey design was a convenient and cost-effective means of collecting data electronically from busy undergraduate students on the electronic teaching platform that they regularly used in the context of their studies.

Total population sampling was used as all students enrolled in the BSc Occupational Therapy degree in 2015 were invited to participate $(n=205)$. The invitation to participate was placed on e-OT, the occupational therapy electronic teaching platform, together with the approved information sheet outlining the research. Students were able to select if they wished to participate or not. While the survey method is convenient, it has a risk of a low response rate and a high chance of non-return bias. Thus, a sample size of I 16 was required according to Cochrane's formula, which set a $5 \%$ margin error.

The research instruments used in this study was a battery of questionnaires used by $\mathrm{Ahern}^{33}$ to measure the resilience of American community college nursing students at the University of Central Florida in Orlando. This battery was used as no resilience measure standardised on the South African late adolescent health science student population could be found in the literature. Ahern provided permission for her battery to be used in this study. The battery consisted of four self- administered questionnaires: a demographic questionnaire $\mathrm{e}^{33}$; the resiliency scale $\mathrm{e}^{34}$; the perceived stress visual analogue scale ${ }^{35}$ and the health behaviours questionnaire ${ }^{36}$

The demographic questionnaire ${ }^{33}$ designed by Ahern was adapted slightly to be more relevant to a South African university student context and sample. The demographic questionnaire included items on age, financial support, living arrangement, housing, activities, study habits, social support and religion. Gender was removed from the questionnaire as a condition of the ethical clearance, as male students could be easily identified due to the low number registered in the programme.

The Resilience Scale (RS) by Wagnild and Young was used ${ }^{34}$. This resilience scale has been used internationally by many researchers and is available in thirty-five languages ${ }^{37}$. It had also been used previously in South Africa to study resilience within the nursing profession ${ }^{38}$. The RS measures resilience in two subscales: Section I Personal Competence that considers self-reliance, independence, mastery, resourcefulness and perseverance. While Section 2 addresses Acceptance of Self and Life considers flexibility, adaptation and a balanced perspective.

The RS consists of 25 items scored on a 7-point scale: ranging from strongly agree to strongly disagree. One extra question can be added at the examiner's discretion. Summed scores on the RS, range from 25 to 175 with the higher scores indicating greater resilience. The scores are ranked into three categories: high (I47- I75), medium $(|2|-\mid 46)$, and low (less than $|2|)$. There are no norms for the subscale scores. This scale is reported to have adequate face validity as these items were validated by Wagnild and Young ${ }^{34}$. Test-retest correlations ranged from ICC of 0.67 to 0.84 , and the questionnaire had reported internal consistency with a Cronbach alpha of 0.72 to 0.94 . Numerous studies have proven and validated the RS, which has shown a significant inverse relationship with measures of psychological distress (depression and anxiety) and positive correlation with measures of well-being (self-esteem and self-efficacy $)^{34,39}$.

The Perceived Stress Scale (PSS) was a self-report visual analogue scale (VAS) used as a global measure of perceived stress ${ }^{35}$. The PSS is reported to be the most widely used instrument to measure the perception of stress. It is suitable to most sub-population groups due to the general nature of the questions and ease of use $\mathrm{e}^{40}$. This scale has been used in South Africa to measure stress in a university student population at the University of Kwa-Zulu Natal ${ }^{41}$. The VAS within the PSS is a uni-dimensional instrument used to quantify the intensity of stress. Due to measurement bias found in relation to the original scale, numbers have been inserted along the horizontal lines to act as anchors to decrease this reported bias. The PSS consists of two scales, the first measures the participants' perceived general stress and the second measures the participants' level of stress at the current time. The VAS scores were measured from 0 to 10 , where zero is 'no stress' and 10 is 'extreme stress'. Cronbach alpha scores of between 0.79 and 0.77 have been reported and the convergent validity to the Depression, Anxiety and Stress Scale DASS-2I was between $r=0.64$ and $r=0.60^{42}$. The VAS test-retest reliability scores range from $0.95-0.9935$

The Health Behaviour Questionnaire (HBQ) is a self-report questionnaire on health related behaviours or experiences during the past twelve months ${ }^{36}$. The HBQ has been used in research in Ghana ${ }^{43}$ but not in South Africa. This questionnaire identifies behavioural risks which describe the participants' willingness to engage in health risk behaviours and emotional risks which includes the reporting of aversive emotions. The questionnaire consists of 27 items requiring a response on a 5-point Likert scale ranging from never (I) to daily (5). A high score on this questionnaire indicates a high level for health risk behaviours. Two positive questions about involvement in religion and volunteer work are scored separately ${ }^{36}$.

The HBQ also has 5 lifetime question items requiring a rating of two options: never or at least once. Reliability of the HBQ behavioural risk scale has a reported Cronbach alpha of 0.84 while the emotional risk scale has a Cronbach alpha of $0.8 \mathrm{I}^{36}$.

These four data collection tools were formatted for an electronic platform. The researchers and their supervisor reviewed and checked electronic version for ease of completion.

The final approved electronic version of the questionnaire together with the approved information sheet was loaded onto the department's e-learning platform. Informed consent was assumed if the questionnaire was submitted electronically. The questionnaire was completely anonymous as there was no identifying information on the questionnaire itself and responses were sent to a repository where the source of the questionnaire could not be identified.

The research battery was available for all students to complete from the beginning of the academic year in January and was open until $15^{\text {th }}$ April of that academic year. Students were given electronic reminder prompts and each class was verbally invited to participate and reminded several times and by the researchers.

\section{Data analysis}

The three questionnaires were scored as prescribed by their authors and all data were transferred to an EXCEL spreadsheet. The demographic data and all other questionnaires were analysed descriptively using frequencies. Using STATISTICA version I3.2, data from the questionnaires were analysed descriptively and median and quartile ranges were reported, as the data were all ordinal. In this battery of questionnaires, the scores of both the RS and HBQ are summed for interpretation purposes. The Kruskal-Wallis ANOVA test was used to determine if there was a significant difference 
between the four years of students for all questionnaires as well as their subtests. Spearman's rank order correlation coefficient was used to determine any associations between the results of the total scores of all questionnaires as well as their subtests for stress and resilience and the health behaviours.

\section{RESULTS}

\section{Demography of the sample}

The sample size of I 8 of registered students who participated in the study fulfilled the sample size requirements and could be considered representative of the population of 205 students. All returned questionnaires were analysed. Due to the small amount of missing data, no further analysis was completed to accommodate this.

The sample consisted of $44(37.6 \%)$ I ${ }^{\text {st }}$ years that presented the highest percentage of the sample, $26(22.2 \%) 2^{\text {nd }}$ years, $29(24.8 \%)$ $3^{\text {rd }}$ year and $18(15.4 \%) 4^{\text {th }}$ years and I unknown.

The highest percentage of the II 4 participants who reported their age, $46.4 \%$ were between 17 and 19 years of age $(n=53)$, while $44.6 \%$ were between $20-22$ years $(n=5 I)$ and only $8.8 \%$ were older than $23(n=10)$.

The majority of 110 participants who indicated the source of funding for their studies reported that their studies were funded by Parental/Family support: $n=74(67 \%)$, with almost equal numbers funded by Financial Aid-loans: $n=18(16 \%)$; and Financial AidBursary: $n=17(15 \%)$; and only $n=2(2 \%)$ having scholarships.

Of the 110 participants who reported on where they lived, the smallest percentage were living alone $n=6(5 \%)$ while most were living with family $n=85(77 \%)$. Others lived with a roommate $n=4(4 \%)$ and $n=15(14 \%)$ lived in a university residence. The majority of these participants reported that their parents provided most social support 73 (7I\%), followed by their peers I 3 (I2\%), siblings $7(6 \%)$, other adults $7(6 \%)$. and finally, other family members $3(3 \%)$ ].

The number of hours per week student spent studying varied greatly. Two students reported not studying at all (2\%), $n=4$ I (36\%) studied for between $\mathrm{I}-\mathrm{I} 0$ hours, $\mathrm{n}=48(42 \%)$ studied between I I-20 hours and $n=23(20 \%)$ studied for more than 20 hours per week. Ninety-three students of the II 4 students (82\%) who answered the question on the length of time they studied reported never having failed a year.

\section{Levels and sources of stress}

One hundred and fourteen participants completed the VAS scale for their perceived stress levels right now and stress in general are recorded for each year (Table I below).

Stress right now was considered high with a median of $70 / 100$ for the total group. There is no significant difference between the year cohorts for stress right now $(p=0.360)$ but stress differed significantly over the year between the four years of students $(p=$ 0.009 ) with stress levels rated highest by the fourth year group. The third year group reported lower stress, but the very wide quartile range indicating the largest range of perceived stress in this cohort. Students perceived the stress over the year was higher than right now, with the median for the group being $80 / 100$.
All students perceived most stressors experienced in the last six months to be academic with scores in a narrow range between the four years of a VAS scale between 57.6 and 65.38 (Figure 2 below). The third year students reported slightly higher academic stress than that reported by the second and fourth year students but had lower personal stress and social stress scores. The fourth year students had the lowest academic stress with the highest personal stress and social stress scores. Personal stress was however much lower than academic stress with a range between 18.6 and 33 for all four years with the scores for social stress being even lower with a range of between 7.69 and 16,67 .

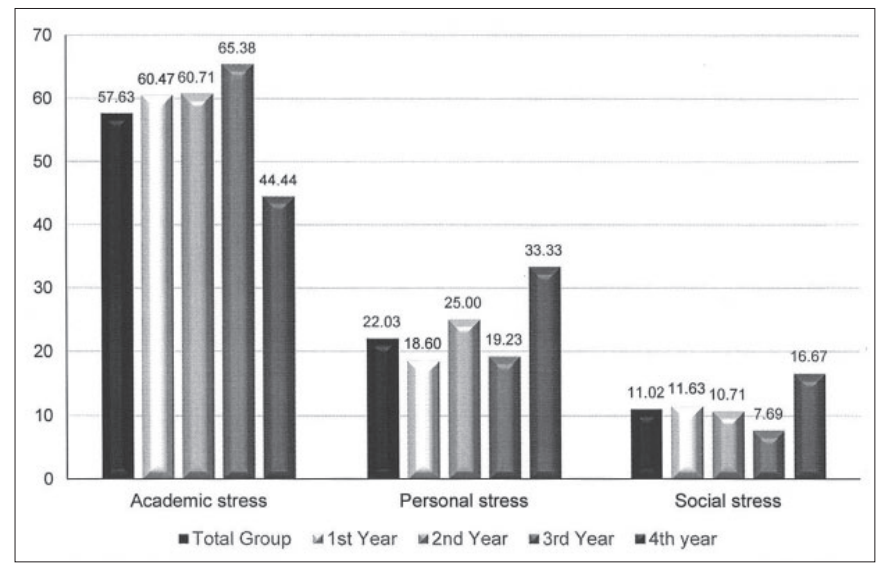

Figure 2: Stressors experienced by participants in last six months $(n=I \mid 4)$

\section{Resilience levels of the sample}

Figure 3 below reports the distribution of the sample scores across the three levels of resilience: low $(<120)$, medium $(121-146)$, and high (147 - 175). Most students fell in the high or medium resilience level, but with approximately $25 \%$ of third and fourth year students in the low resilience category.

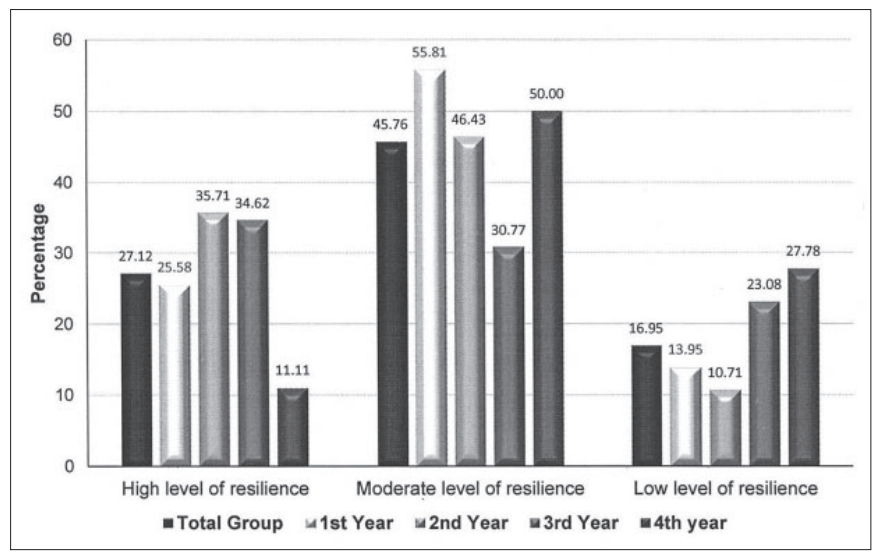

Figure 3: Distribution of the sample in the categories of resilience $(n=I \mid 4)$

Table I: Stress on VAS scale (0-100)

\begin{tabular}{|c|c|c|c|c|c|c|c|}
\hline & & \multicolumn{3}{|c|}{ Stress right now } & \multicolumn{3}{|c|}{ Stress in general over the year } \\
\hline & \multirow[t]{2}{*}{$\mathbf{n}$} & Median & Lower and upper quartiles & $p$ value & Median & Lower and upper quartiles & p value \\
\hline & & \multicolumn{2}{|r|}{ Score 0-100 } & & \multicolumn{2}{|r|}{ Score 0-100 } & \\
\hline Total Group & 114 & 70 & $60-80$ & & 80 & $66-85$ & \\
\hline$I^{\text {st }}$ year & 43 & 70 & $60-76$ & 0.360 & 79 & $66.5-85.5$ & 0.009 \\
\hline $2^{\text {nd }}$ year & 26 & 70 & $59-75$ & & 76 & $60-85$ & \\
\hline $3^{\text {rd }}$ year & 28 & 68 & $55-80$ & & 73 & $53-85$ & \\
\hline $4^{\text {th }}$ year & 17 & 67 & $60-81$ & & 80 & $75-88$ & \\
\hline
\end{tabular}


Table II: Results of the Resilience Scale (RS)

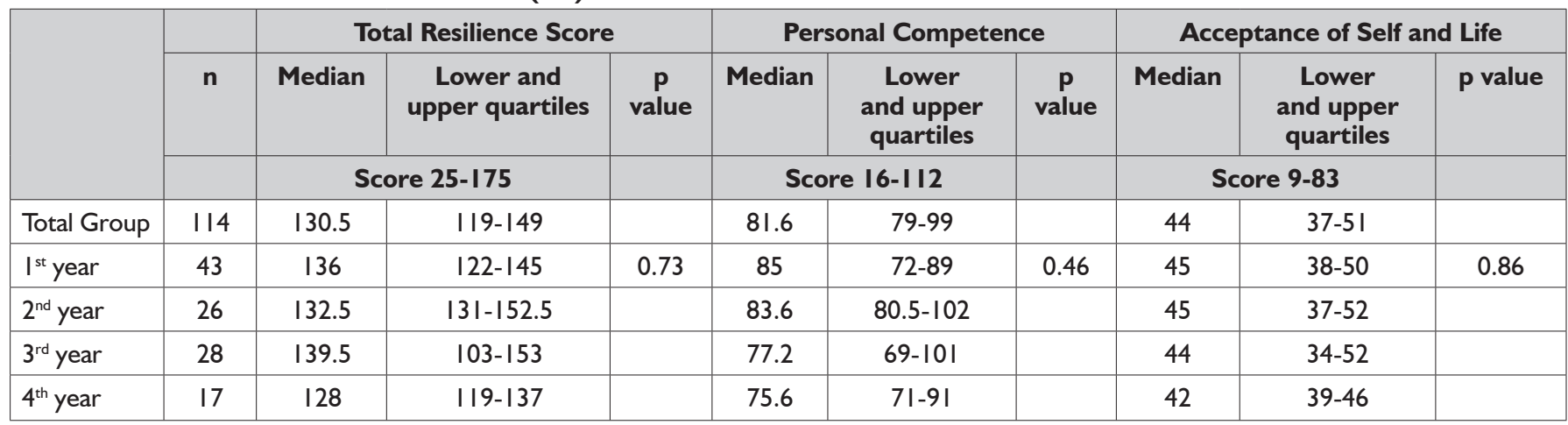

Table III: Results of the Health Behaviour Questionnaire (HBQ)

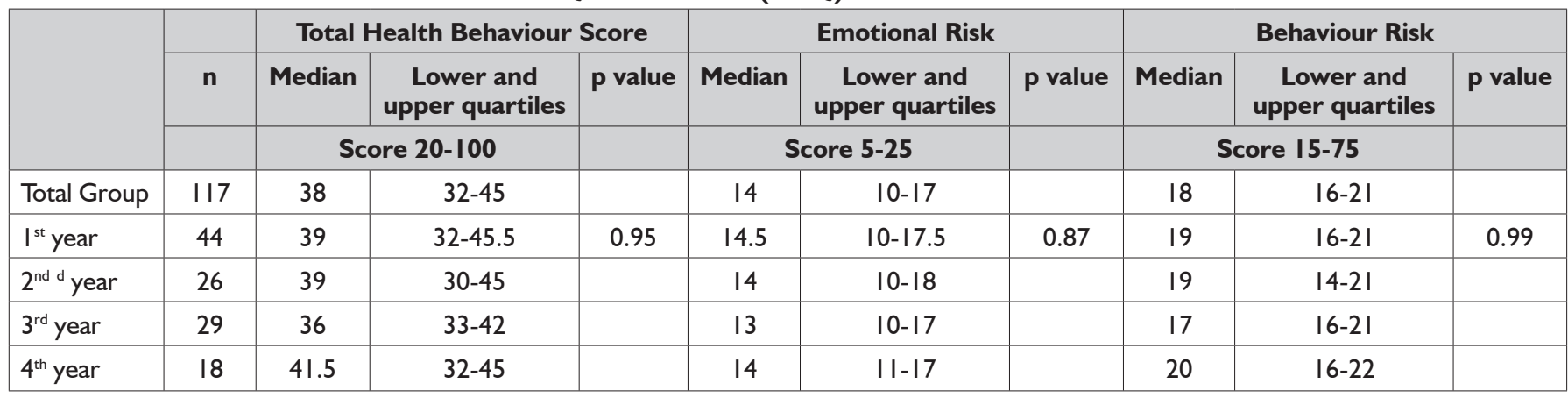

There were no significant differences between the years of students on any of the scores on the RS (Table II above). The median total resilience score for most of the II 4 students who answered the questionnaire fell in the medium range of resilience (I 21 - I 46 at $74.5 \%$ of the total score), although there was some variation in the lower and upper quartile ranges.

Although the third year group had the highest median score for resilience, this group had the lowest lower quartile score suggesting that a number of participants in this group had poor resilience. Although the fourth years fell within the medium resilience range, their lower quartile range indicated, some participants had lower resilience than the first and second years.

Similar results were found for the Personal Competence scores and the Acceptance of Self and Life scores within the RS for each of the four years of students although the median resilience was lower in both sections than for total resilience. The median for the total group of the former is at 81.6 (at $70 \%$ of the total score), while the median score for the total group in the latter is 44 (at the $50 \%$ of the total score) indicating lower resilience for Acceptance of self and life.

\section{The Health Behaviour Questionnaire (HBQ)}

There were no significant differences between the year cohorts of students on this questionnaire (Table III above). The total HBQ score suggests that the participants have a low $( \pm 40 \%)$ risk for behaviours that compromised their health in general. The fourth year students had the highest median score although the quartile range is similar to other groups. Scores on the Behaviour risk section of the HBQ are similar in all year cohorts with a low risk of between 22\%-26\% of the total score of 75 . While fourth year students also had a higher median score and quartile range for Behaviour risk scores, for all years of students on the Emotional risk section of the HBQ were similar. This section indicated that students have a higher emotional risk at $54-60 \%$ of the total score of 25 .

Results for the two items on the HBQ, which indicate positive behaviour, not aligned with risk and support health- "I attend religious services" and "I do volunteer work" were scored separately (Figures 4 and 5 on the right).

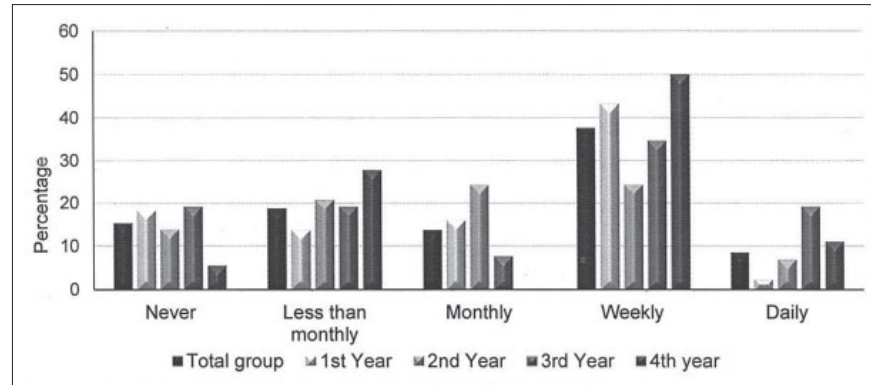

Figure 4: Results of the question 'I attend religious services' $(n=I \mid 7)$

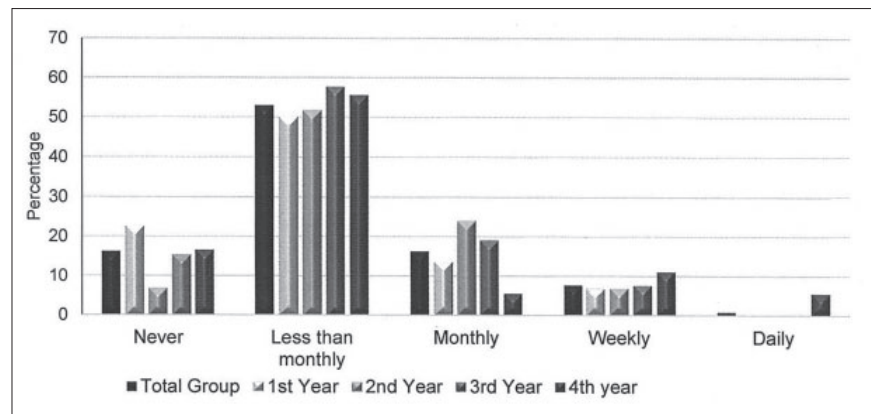

Figure 5: Results of the question 'I do volunteer work' $(n=117)$

Approximately $85 \%$ of participants attend religious services, but with considerable variation in the frequency. The highest number attended religious services weekly. More than $50 \%$ of participants reported engaging in volunteer work, and most commonly only once a month.

Results from the lifetime questions indicated that one participant reported having been arrested, two had been expelled from school, one had fallen pregnant, six had attempted suicide and three reported having run away from home. 


\section{Correlation between stress, resilience and at risk behaviour}

As can be seen in Table IV below only one variable had a significant correlation $(p \leq 0.05)$ which suggests the behavioural risks increase with stress during the year. All correlations were low indicating no association between these factors.

Table IV: Correlation between stress, resilience and at risk behaviour $(n=|| 4)$

\begin{tabular}{|l|c|c|c|}
\hline & \multicolumn{3}{|c|}{ Spearman Rank Order Correlations (r value) } \\
\hline Variable & Total risk & $\begin{array}{c}\text { Stress right } \\
\text { now }\end{array}$ & $\begin{array}{c}\text { Stress during } \\
\text { this year of study }\end{array}$ \\
\hline Total risk & -0.03 & -0.10 \\
\hline Total resilience & 0.14 & -0.16 & -0.14 \\
\hline $\begin{array}{l}\text { Personal com- } \\
\text { petence }\end{array}$ & -0.05 & -0.09 \\
\hline $\begin{array}{l}\text { Acceptance self } \\
\text { and life }\end{array}$ & -0.09 & -0.10 \\
\hline Behavior risk & -0.01 & $-0.19 *$ \\
\hline Emotional risk & 0.04 & 0.03 \\
\hline Significance $\mathrm{p} \leq 0.05$ & & \\
\hline
\end{tabular}

\section{DISCUSSION}

The participant response rate of $57 \%$ is considered good for an on-line survey, as according to Nulty an average return rate of online surveys by students is $33 \%{ }^{42}$. The sample distribution across the years of study was representative of the number of students in each class with the most students in the first year and the least in the final year. This sample reported a high annual pass rate and thus most participants expected to complete the programme in minimum time. Only the first year students, had not yet written an examination so were not able indicate their pass/failure status, which may have inflated the pass rate result. However, the figure of $82 \%$ is consistent with the average pass rates reported by the University in $2017^{44}$.

In this sample, parents paid the university fees of the majority of respondents. Thirty percent of the sample reported that the National Student Financial Aid Scheme (NSFAS) financed their university education either in the form of loans or bursaries. At the time of this study, this fund was available to students whose families earned less than RI0166.00 per month ${ }^{45}$. In response to the "Fees must fall" protest action in 2016 and 2017 and the pronouncement of free education by the President at the end of 2017, the threshold for NSFAS funding was increased at beginning of $2018^{46}$. Linked to this variation in the source of funding in this cohort of students is the socioeconomic background of the participants, with most students being from high to middle-income groups. Similarly, the majority of the participants in this study reported living at home with their family, which may suggest that the choice of this occupational therapy programme may have been motivated by the fact that the university was local, the policy to limit accommodation offered to local students and the high cost of university accommodation. A similar trend has been reported in both UK and the USA ${ }^{47,48}$. This is also a similar trend to that reported in the Ahern and $\mathrm{Norris}^{30}$ and Ahern study ${ }^{33}$. A low number of students lived in places other than their home, with only $14 \%$ staying in the university residence. This number is similar to the number of students with NSFAS funding which often covers both tuition and residence fees. This is consistent with 20 I I Ministerial Committee report on student housing at South African universities reported that residences accommodated $15.0 \%$ of the registered students at Wits, most residence students were supported by financial aid ${ }^{49}$.

Eighty three percent of participants reported their immediate and extended family as their main source of social support and this has been associated with higher resilience. This result was similar to that in the Ahern and Norris study ${ }^{30}$. This may be a consequence of most participants living at home with their families, as well as their relative youth with $90 \%$ of the sample under the age of 22 years. Social support from peers was rated surprisingly low, considering their developmental age band where the support of peers has been reported to be significant.

Within in this sample more than $61 \%$ of participants reported that they studied for II-20 hours per week, which is greater than the students in the Ahern and Norris study, where most subjects $(86 \%)$ studied between I and 10 hours ${ }^{30}$. This is a high workload, considering that these study hours were over and above their almost full-day university lecture programme in the first 3 years of study and are additional to their 35-hour week in clinical practice settings in the final year. This gives some support to the occupational therapy students feeling that they have a high workload. Whether the workload is actually higher than students in comparable health professional programmes could not be confirmed, as no specific figures reporting workload hours could be found to support their view. Despite this, the reported high workload for occupational therapy students is consistent with other studies on occupational therapy students ${ }^{4,11,14}$.

\section{Levels and source of stress of all students registered in the programme}

The participants in this study perceived their stress levels right now and over the past year to be high, well over the $50 \%$ mark on the VAS scale. This is consistent with other studies that have examined the stress levels of occupational therapy students both nationally and internationally $5,8,11,14$. The stress levels reported by participants right now were marginally lower than those reported over the past year but both median scores where higher than reported in the Ahern and Norris study ${ }^{30}$. This is probably a reflection of the time of year when the data were collected. The perceived stress levels of the first and second year students right now were higher than that of the more senior students (third and fourth years). The first years were in the first semester of their university career and were adjusting to teaching and learning in the university context and university life, which is reported to be a stressful transition in other literature ${ }^{50,51}$. The second years had just started a demanding academic programme including courses in anatomy and physiology, which both have high failure rates and high volumes of work. While no studies could be found to support or refute the impact of anatomy and physiology courses on the stress levels of occupational therapy students, courses with a high workload and courses which create concerns around failure have been reported to be a source of stress ${ }^{1.14}$. It is assumed that this early part of the year is less stressful for the more senior students as assignment deadlines, routine evaluations and clinical practice demands are less evident at this time of the year.

The high levels of stress in the past year for all participants was reported to be mainly academic which is consistent with what is reported above and in other studies of occupational therapy students and health science students', II. The first and final year participants recorded the highest perceived general stress over the past year. For the first year students this may reflect the stress around the final senior certificate examination on which the students' future and acceptance into the university programme of their choice was dependant. For the final years, this may reflect programme specific stressors related to their third year experience. In this programme students complete their first extended period of clinical practice, their first clinical examinations as well as the highly pressurised workload and examination period due to the nine courses that have to be completed at this time to ensure progression to the final year.

Not surprisingly, most participants reported their greatest source of stress to be academic, smaller percentages of participants reported their source of stress to be personal and social, with the highest percentages being in the final year. While the 
nature of these stressors was not explored, anecdotal evidence suggests that most of the personal difficulties in the final year are associated with completing clinical blocks away from the campus, which created financial strain from additional travelling and accommodation costs as well as the carer burden when dealing with clients. These personal stressors have been reported in other occupational therapy literature ${ }^{52}$. Personal stressors of a more social nature have also been reported relating to complex interpersonal relations with parents, peers, supervisors and relationships that are more intimate ${ }^{53}$.

\section{The resilience levels and health behaviours of participants}

Although the Ahern and Norris study ${ }^{30}$ was conducted in the United States America, it was conducted on a similar group of health professional students of a similar age band and similar higher education context to this current study. In spite of this, it is difficult to accurately interpret the results on this South African cohort. No other study used this health behaviour scale with reference to occupational therapy students thus the similarity and differences are of interest.

Although there was some variation in the resilience scores between the participants across the four years of the programme, these were not significant and the majority of participants scored within the medium range of resilience. This result was consistent with the Ahern and Norris study ${ }^{30}$. In all years, the personal competence scores were generally higher than the acceptance of self and life scores, although the personal competence median score were lower than were found by Ahern and Norris ${ }^{30}$.

As a group, occupational therapy student participants had more difficulties with acceptance of self and life than with personal competence, with very similar median scores and quartile ranges in each year. Although the scores were somewhat lower than the Ahern and Norris study ${ }^{30}$, it is difficult to evaluate their specific implication as there have been no other studies that have reported using these tools to examine resilience in South African occupational therapy students. Although, unrelated to resilience, a study by Holland et. al. ${ }^{54}$ suggested that acceptance of self as a professional is an evolving skill and related to professional confidence which may be closely linked to resilience. In occupational therapy training emphasis is placed on selfawareness and students are expected to become self-aware of and implement therapeutic use of self, which may make students vulnerable, as they reflect on who they are, what they are doing and what they are becoming. These questions in turn may influence their resilience in this aspect ${ }^{55}$. This raises the question as to whether having mid-range level of resilience' is sufficient to counteract the effects self-acceptance and professional identity as professional and programme related stress in occupational therapy students.

This cohort of participants reported a low risk of emotional and behaviour indicators of stress on the $\mathrm{HBQ}$. It appears that students in the occupational therapy course use fewer risk behaviours to deal with stress despite reporting high levels of stress, as the median scores were lower than those reported by Ahern and Norris $^{30}$ in their study. These findings were also different to the behavioural indicators of stress reported in South African health science students in other studies where higher levels of substance abuse were reported $d^{2,30}$.

Eighty-five percent of the participants reported involvement in religious activities at least once a week. It is uncertain as whether the frequency of involvement, as measured in the study, acts as a protective factor against stress and/or plays a role in the management of stress. This view was also reported by Ahern and Norris $^{30}$. However, a more comprehensive study by Ahlers, Mezulis and Hudson found that religion was only a buffer to stress in individuals with high religious commitment, which may perhaps only be relevant to the participants attended religious activities very frequently ${ }^{56}$.

\section{The association between stress and resilience and the health behaviours of these students}

A significant association was found for stress over the course of the year increasing risk taking behaviours in this cohort of students $(r=-0.19)$. Although this study did not ask participants what risk taking behaviours they engaged in, a number of studies have identified risk taking behaviours as including heavy drinking, tobacco and marijuana use and hook-up sex associated with university students ${ }^{57,58}$. Although the participants reported that as the stress levels rose over the course of the year, which potentially increased the risky health behaviours, this study found that overall the evidence of risk taking behaviour was low. This may be associated with the fact that many of the participants stayed at home which may have had a moderating influence on risk taking behaviours. The engagement of many participants in religious activities may also have contributed to this.

\section{Limitations of the study}

This study intended to study the Wits occupational therapy student cohort and their resilience in the context of their education programme. Thus, the findings of this study cannot be generalised to other occupational therapy student groups, which have different characteristics, which may influence their resilience. The cross-sectional nature of this study meant that the measurement of variables in this study occurred only once and therefore did not reflect variations in stress levels over the course of the year. The fact that data were collected during the first semester, may have influenced the results. A survey design was used for convenience and reported students' perceptions of their stress levels rather than their actual stress levels, which in some studies have been reported to be different. Student were able to self-select participation and findings may have been different if the 87 who decided not to participate had been included. At the time of the data collection, no academic data or test and assignment progress data were collected, these factors may have accounted for high stress levels but were not measured.

Male students were excluded from the study due to ethical concerns that they may be easily identified, as their numbers were very low. It was thus not possible to examine the similarities and differences of both stress and resilience between the genders which had been described in other studies ${ }^{23,33}$.

\section{CONCLUSION}

This study appears to confirm the occupational therapy students' assertion that they have high programme-related stress. Whether programmatic stress is more or less than comparative programmes in the Wits Health Science Faculty cannot be denied or confirmed, as this was not the focus of the study. The results also suggest that most students have moderate levels of resilience as well as high levels of family support to moderate these mostly academic stressors. Although stress over the year was reported to increase health risk behaviour, the risk in this cohort was found to be low.

The purpose of this study was to identify if occupational therapy students registered at this university required some resilience training to improve their management of their high stress levels. Literature suggests that these programmes do increase resilience and therefore may be helpful to all students. Students who report high personal stress in addition to academic stress and who are far from their families or do not have good family support should be targeted for such programmes, as they appear to be particularly vulnerable.

Future research should aim to compare the stress levels and resilience of students in comparable courses to students in the occupational therapy programme. Some resilience training should be offered to students to promote mental health self-care and the effects of the evaluated. 


\section{REFERENCES}

I. Stecker T. Well-being in an academic environment. Medical Education 2004; 38(4): 465-478.

https://doi.org/10.1046/j. I365-2929.2004.01812.x.

2. van Zyl PM, Joubert G, Bowen E, et al. Depression, anxiety, stress and substance use in medical students in a 5-year curriculum. African Journal of Health Professions Education. 2017; 9(2): 67-72. https://doi.org/10.7196/AJHPE.2017.v9i2.705.

3. Mc Allister $M$ and McKinnon J. The importance of teaching and learning resilience in the health disciplines: A critical review of the literature. Nurse Education. 2009; 29(4): 37I. https://doi.org/10.1016/j.nedt.2008.10.011.

4. Robins T, Roberts $R$ and Sarris $A$. The role of student burnout in predicting future burnout: exploring the transition from university to the workplace. Higher Education Research and Development. 20 I8; 37(I): I15-130. https://doi.org/10.1080/07294360.2017.1344827.

5. Swanepoel A. Factors influencing academic success of first year occupational therapy students Dissertation, University of the Free State, Bloemfontein, 2014.

6. Pillay A and Ngcobo H. Sources of stress and support among ruralbased first year university students: an exploratory study South African Journal of Psychology. 2010; 40(3): 234-240.

https://doi.org/10.1 I77/008|2463 I004000302.

7. Theron $L$ and Theron $A$. Education services and resilience processes: Resilient Black South African student experiences. Child and Youth Services Review. 2014; 47(3): 297-306.

https://doi.org/10.1016/j.childyouth.2014.10.003.

8. Janse van Rensberg $V$ and Kapp R. 'So I have to be positive, no matter how difficult it is': a longitudinal case study of a first-generation occupational therapy student. South African Journal of Occupational Therapy. 2014; 44(3): 29-33.

9. Khawaja N, Ibrahim $\mathrm{O}$ and Schweitzer R. Mental Wellbeing of Students from Refugee and Migrant Backgrounds: The Mediating of Resilience. School Mental Health. 2017; 9(3): 284-293. https://doi.org//0.1007/s I 2310-017-9215-6.

10. Busari A. Identifying differences in perception of academic stress and reactions to stressors based on Gender among first year university students. International Journal of Humanities and Social Sciences. 2012; 2(14): 138-478.

II. Everly J, Poff D, Lamport N, et al. Perceived stressors and coping strategies of occupational therapy students. American Journal of Occupational Therapy. 1994; 48(I I): 1022-1028. https://doi.org/10.5014/ajot.48.II.1022.

12. Bonsaksen T. Predictors of General Self-efficacy and Self-esteem in Occupational Therapy Students: A cross-sectional study. Occupational Therapy in Mental Health. 20I5; 31 (3): 298-3I0. https://doi.org/10.1080/0164212X.2015.1055536.

13. Wimpenny $\mathrm{K}$ and Lewis L. Preparation for an uncertain world: Professional agency and durability in practice preparation of mental health in occupational therapy. South African Journal of Occupational Therapy. 2015; 45(2): 22-28. https://doi.org/10.17159/2310-3833/2015/V45N2A5.

14. Pfeifer T, Kranz P and Scoggin A. Perceived stress in occupational therapy students Occupational Therapy International 2008; I5(4): 22 I-23I. https://doi.org/10.1002/oti.256.

15. World Federation of Occupational Therapy. Minimum Standards for the Education of Occupational Therapists- revised. 2016 WFOT; 2016: 80.

16. Edwards $\mathrm{H}$ and Dirette D. The relationship between Professional Identity and Burnout among Occupational Therapists. Occupational Therapy in Health Care 2010; 24(2): II9-129. https://doi.org//0.3109/07380570903329610.

17. Holland K, Middleton L and Uys L. Professional confidence held by novice occupational therapists in South Africa. Occupational Therapy International. 2013; 20(3): 105-I I3. https://doi.org/10.1002/oti. 1340.

18. Delany C, Miller K, El-Ansary D, et al. Replacing Stressful Challenges with Positive Coping Strategies: A Resilience Program for Clinical Placement. Advances in Health Science Education. -online 2015. 20(5): 1303-1324.

https://doi.org/10.1007/s 10459-015-9603-3.

19. Stew G. Mindfulness training for occupational therapy students.
British Journal of Occupational Therapy. 20I I; 74(6): 269-276. https://doi.org/10.4276\%2F0308022 I IXI3074383957869.

20. Myers S, Sweeny A, Popick V, et al. Self Care Practices and Perceived Stress Levels amongst Psychology Graduate Students. Training and Education in Professional Psychology. 2012; 6(I): 55-66. https://psycnet.apa.org/doi//0.1037/a0026534.

21. Ashby S, Ryan S, Gray M, et al. Factors that influence the professional resilience of occupational therapists in mental health practices. Australian Occupational Therapy Journal. 2013; 60(2): I I0-1 I9. https://doi.org/10. I I I //1440-1630.12012.

22. Jackson D, Firtko $A$ and Edenborough M. Personality resilience as a strategy for surviving and thriving in the face of workplace adversity: a literature review. Journal of Advanced Nursing 2007; 60(I): I-9. https://doi.org/ I0. I I I I/j. I365-2648.2007.044 I 2.x.

23. Erdogan E, Ozdogan $O$ and Erdogan M. University Student's Resilience Level:The Effect of Gender and Faculty. Pocedia-Social and Behavioral Sciences. 2015; 186(10): I262-1267. https://doi.org//0.1016/j.sbspro.2015.04.047.

24. Wu G, Feder A, Cohen $\mathrm{H}$, et al. Understanding Resilience. Frontiers in Behavioral Neuroscience. 201 3; 7(10): 32. https://doi.org/10.3389/fnbeh.2013.00010

25. Mejia-Downs A. Resilience: Everybody has it-what will you do with yours? Cardiopulmonary Physical Therapy Journal. 201 7: 28(3): 9398. 10.1097/CPT.0000000000000062.

26. Brown T, Williams B and Etherington J. Emotional Intelligence and Personality Traits as predictors of Occupational Therapy students' Practice Education Performance: A cross-sectional study. Occupational Therapy International. 2016; 23(4): 4I 2-424. https://doi.org/10.1002/oti. I443.

27. Tugade $M$ and Fredrickson $B$. Resilient individuals use positive emotions to bouce back from negative emotional experiences. Journal of Personality and Social Psychology. 2004; 86(3): 320-333. http://dx.doi.org/|10.1037/0022-35|4.86.2.320.

28. Orkibi H. Highly artistic-social personalities buffer the effects of burn out on career commitment. The Arts in Psychology. 2016; 50(9): 75-83. https://doi.org/10.1016/j.aip.2016.06.006.

29. Poulsen A, Meredith P, Khan A, et al. Burnout and work engagement in occupational therapists. British Journal of Occupational Therapy. 2014; 77(3): I-9. https://doi.org/10.4276/0308022 |4X|394 I03626662 I

30. Ahern $\mathrm{N}$ and Norris $\mathrm{A}$. Examining factors that increase and decrease stress in adolescent community college students. Journal of Pediatric Nursing. 20 I I; 26(6): 530-540.

31. Garmezy N, Masten A and Tellegen A. The study of stress and competence in children: A building block of developmental psychopathology. Child Development. I984; 55(I): 97- I I I.

32. Luthar S. Vulnerability and Resilience: a study of High risk adolescents. Child Development. 1991; 62(3): 600-616.

33. Ahern N. Resiliency In Adolescent College Students. Electronic dissertation. 2007. Florida: University of Central Florida. [cited 2017 Jun 6]. Available at: https://stars.library.ucf.edu/cgi/viewcontent.cgi?referer=https:// www.google.com/\&httpsredir $=\mid$ \&article $=4049 \&$ context $=$ etd .

34. Wagnild $G$ and Young $H$. Development and psychometric evaluation of the Resilience Scale. Journal of Nursing Measurement. I993; I (2): I65- I 78.

35. Mitchell A, Crane P and KIM Y. Perceived stress in survivors of suicide: Psychometric properties of the Perceived Stress Scale. Research in Nursing and Health 2008; 31 (6): 576-585. https://doi.org/10.1002/nur.20284.

36. Ingersoll $\mathrm{G}$ and Orr D. Behavioral and emotional risk in early adolescents. Journal of Early Adolescent 1989; 9(4): 396-408. https://doi.org/I0. I I 77\%2F027243 I689094002.

37. The Resilience Centre. Resilience Scale. 2018; [cited 2018 March 8] Available at: www.resiliencecentre.com/resilience-scale/.

38. Koen $M$, van Eeden $C$ and Wissing $M$. The prevalence of resilience in a group of professional nurses. Health SA Gesondheid. 201 I; I6(I): I-II.

39. Wagnild G. A Review of the Resilience Scale. Journal of Nursing Measurement. 2009; I7(2): I05-II3.

40. Cohen S, Karmarck T and Mermelstein R. A Global measure of perceived Stress. Journal of Health and Social Behaviour. 1983; 24(4): 384-396. 
4I. Pilane M. Perceived stress, perceived social support and general well-being among University of KwaZulu-Natal first year students. University of KwaZulu-Natal, Durban, 20I I.

42. Nulty $D$. The adequacy of response rates to online and paper surveys: what can be done. Journal of Assessment and Evaluation. 2008; 33(3): 30I-3l4. https://doi.org/10.1080/02602930701293231.

43. Taylor ME and Owusu-Banahene NO. Stress among part-time business students: A study in a Ghanaian university campus. IFE Psychologia: An International Journal. 2010; I8(I): I I2- 129.

44. University of the Witwatersrand. Facts and Figures 2017-2018. 2018; [cited 2018 April 16] Available at: https://www.wits.ac.za/about-wits/facts-and-figures.

45. Africa Check. Funding the Changing Face of South African Public Universities, 2016; [cited 2018 May 3] Available at: https://africacheck.org/factsheet/factsheet-funding-changing-facesas-public-universities.

46. Zwane S. Statement on the pronouncement of free education. Petoria: National Student Bursary Aid Scheme, 2018; [cited 2018 Apr 5].Available at:

http://www.nsfas.org.za/content/media-releases/Statement\%20regarding\%20the\%20pronouncement\%20on\%20free\%20education.pdf.

47. Wilks S. Resilience amid academic stress: the moderating impact of social support amongst social work students. Advances in Social work. 2008; 2(9): 20I-I25. https://doi.org/10.18060/5I.

48. Kotter T, Pohontsch $\mathrm{N}$ and Voltner E. Stressors and starting points for health promoting interventions in medical schools from the students perspectives: a qualitative study. Perspectives on Medical Education. 2015; 4(3): 128-135. 10.1007/40037-0I5-0189-5.

49. Department of Higher Education and Training. Report on the Ministerial Committee for the review of the provision of student housing at South African universities, 201 I; [cited 2018 May 20].Available at https://www.gov.za/documents/report-ministerial-committeereview-provision-student-housing-south-african-universities.

50. Bojuwoye D. Stressful Experiences of First Year Students of Selected Universities in South Africa. Counseling Psychology Quarterly. 2002; 15(3): 277-290.

https://doi.org/10.1080/09515070210143480.
5I. Parker J, Summerfeldt L, Hogan M, et al. Emotional Intelligence and Academic Success: examining the transition from high school to university. Personality and Individual Differences. 2004; 36(I): I63-I 72. https://doi.org/10.1016/S0191-8869(03)00076-X.

52. Govender P, Mkhabela M, Hlongwane $M$, et al. OT student's experience of stress and coping. South African Journal of Occupational Therapy. 2015; 45(3): 34-39.

https://dx.doi.org/10.17159/2310-3833/2015/v45n3/a7.

53. Soeker S. Occupational therapy student's perception of the challenges they experience in adapting to psychiatric fieldwork placement. Education Research Journal. 20I4; 4(6): 65-73.

54. Holland K, Middleton L and Uys L. Professional Confidence: A concept analysis. Scandinavian Journal of Occupational Therapy. 2010; 19(2): 214-224.

https://doi.org/10.3109/1 1038128.201 I.583939.

55. Wong SR. Therapeutic Use of Self in Occupational Therapy: Applying the Intentional Relationship Model. PhD Thesis, University of Illinois. 2016; cited 2018 Feb 4] Available at: http://hdl.handle.net/I0027/2I 339.

56. Gorgia FE, Paez D, Reyes-Reyes A, Alvarez R. Religious coping as moderator of psychological responses to stressful events: A longitudinal study. Religions. 2017; 8(4): 62. https:doi.org. 10.3390/rel8040062.

57. Chen $Y$ and Feely H. Predicting Binge Drinking in College Students: Rational beliefs, Stress or Loneliness? Journal of Drug Education. 2015; 45(3-4): 133-155. https://doi.org/I0. I I 77\%2F00472379I66398I 2.

58. Meil W, LaPorte D, Mills J, et al. Sensation seeking and executive deficits in relation to alcohol, tobacco and marijuana use frequency among university students: Value of ecologically based measures. Addictive Behaviours. 2016; 62(I I): I35-I44. https://doi.org/10.1016/j.addbeh.2016.06.014.

\section{Corresponding Author}

*PA de Witt

Email: patricia.de witt@wits.ac.za 